\title{
CDKD: a clinical database of kidney diseases
}

\author{
Sanjay Kr Singh ${ }^{1 *}$, Adeel Malik ${ }^{1,3}$, Ahmad Firoz ${ }^{1,4}$ and Vivekanand Jha ${ }^{1,2^{*}}$
}

\begin{abstract}
Background: The main function of the kidneys is to remove waste products and excess water from the blood. Loss of kidney function leads to various health issues, such as anemia, high blood pressure, bone disease, disorders of cholesterol. The main objective of this database system is to store the personal and laboratory investigatory details of patients with kidney disease. The emphasis is on experimental results relevant to quantitative renal physiology, with a particular focus on data relevant for evaluation of parameters in statistical models of renal function.

Description: Clinical database of kidney diseases (CDKD) has been developed with patient confidentiality and data security as a top priority. It can make comparative analysis of one or more parameters of patient's record and includes the information of about whole range of data including demographics, medical history, laboratory test results, vital signs, personal statistics like age and weight.

Conclusions: The goal of this database is to make kidney-related physiological data easily available to the scientific community and to maintain \& retain patient's record. As a Web based application it permits physician to see, edit and annotate a patient record from anywhere and anytime while maintaining the confidentiality of the personal record. It also allows statistical analysis of all data.
\end{abstract}

\section{Background}

Kidney disease is a disorder in which the normal functioning of the kidneys with respect to filtration, reabsorption, secretion, etc., is affected. Chronic kidney disease (CKD) has become one of the most important, chronic, noncommunicable disease epidemics in the world, including India [1].

It is estimated that each year in United States more than 100,000 individuals are diagnosed with kidney disease, a condition in which the kidneys fail to remove the body wastes [2]. Similarly, about 175,000 new patients every year in India develop potentially fatal end-stage renal failure (ESRF) [3]. This generates a huge amount of patient data and requires a proper and efficient way of handling patient record.

India has the largest number of diabetic patients in the world, estimated to be $\sim 40.9$ million in the year 2007 and expected to increase to $\sim 69.9$ million by the year 2025 [4]. Nearly 30\% of ESRF in India is due to diabetic nephropathy. Diabetic nephropathy is clinically defined by the presence

\footnotetext{
*Correspondence: sanjaybiosoft@gmail.com; vjha@pginephro.org ${ }^{1}$ Biomedical Informatics Centre, Post Graduate Institute of Medical Education and Research (PGIMER), Chandigarh 160012, India

${ }^{2}$ Department of Nephrology, Post Graduate Institute of Medical Education and Research (PGIMER), Chandigarh 160012, India

Full list of author information is available at the end of the article
}

of persistent proteinuria of $>500 \mathrm{mg} /$ day in a diabetic patient [5]. A glomerular filtration rate (GFR) $<60 \mathrm{~mL} / \mathrm{min} /$ $1.73 \mathrm{~m}^{2}$ for 3 months or more is defined as kidney damage [6].

The first Asian Forum of Chronic Kidney Disease Initiative (AFCKDI) meeting was held in Hamamatsu, Japan in May 2007. Nephrologists from 16 countries of the AsiaPacific active in the field of chronic kidney disease (CKD) presented 56 papers. Mission of the Asian Forum of Chronic Kidney Disease Initiative was to develop a consensus on a protocol for CKD detection in our region, to analyze risk factors and cost-effective evaluations of proposed interventions, to establish a CKD Initiative network in our region and to contribute to the broader global initiative by using local resources [7].

The exact prevalence of chronic kidney disease in India is not clear in the absence of regular national registry data. The available data is provided only by small observational series or relies on reports from personal experience, but the quality of data is quite uneven [8].

Health-care journals and magazines have touted Electronic Medical records as a means to dramatically improve physician efficiency (productivity and cost) and effectiveness (quality of care). The implementation of an EMR would reduce the need for redundant data collection and 


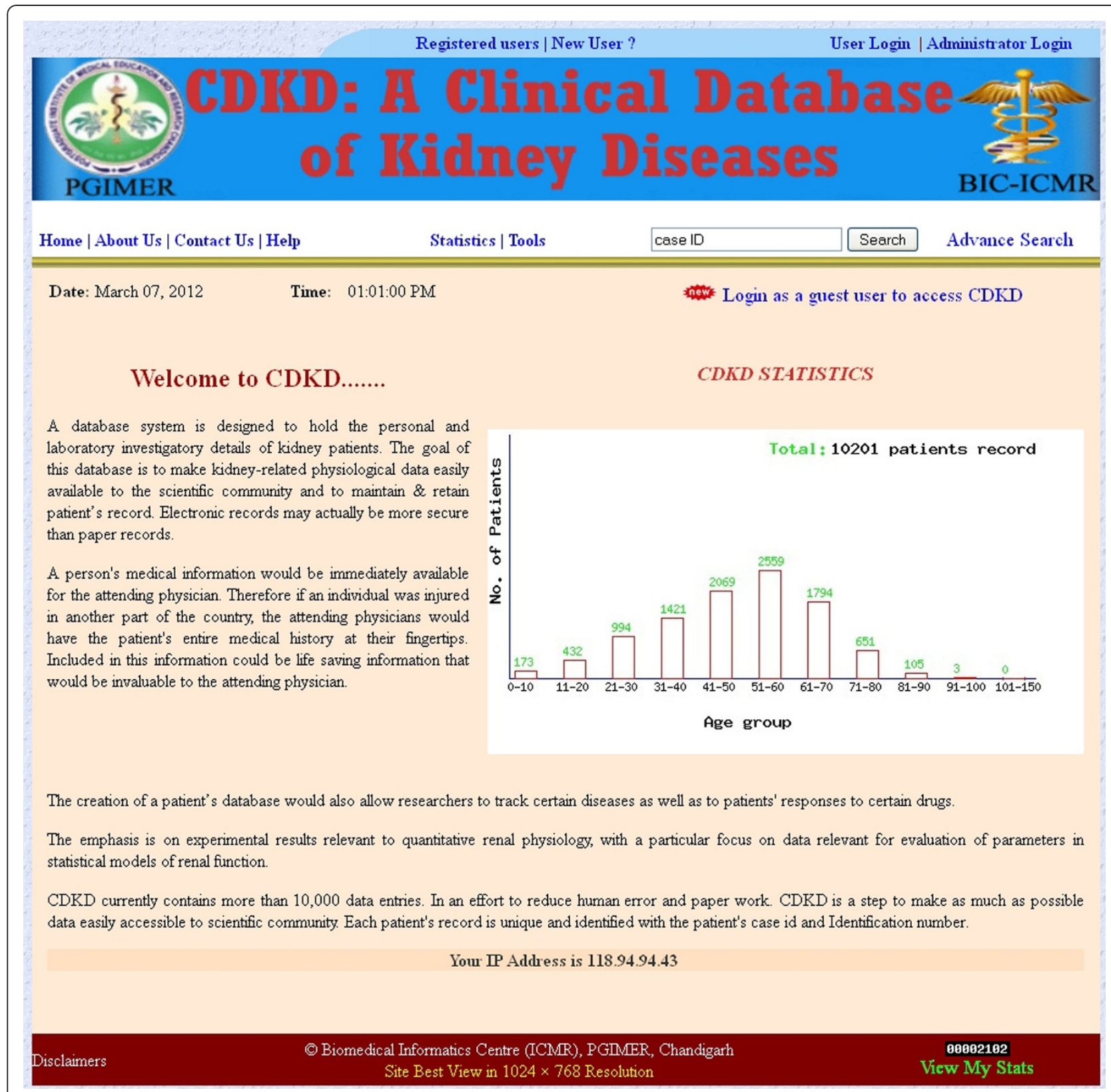

Figure 1 Home page of CDKD. Brief description of CDKD is available on this page and a bar chart is also generated dynamically displaying total number of patients (in an age wise manner). In bar chart the $\mathrm{X}$-axis displays number of patients and the $\mathrm{Y}$-axis shows age group. Over the bar, number of patients relevant to age group is displayed in green color.

allow care providers to quickly review the history and update the medical records wherever necessary. In those cases where the patient or family is unable to provide medical history, having prior data would be invaluable [9].

The fundamental approach of database must be better patient care. The main characteristics of medical records are unrestricted nature, dataflow around the physician/ researcher, and statistical analysis of records [10].

The system requires a robust security infrastructure to support authentication, confidentiality, and data integrity.
To access the patient record, the patient must be identified uniquely and securely while allowing the physician to visualize, edit and annotate a patient record [11].

Error reduction, quality improvement and lowering of cost can all be achieved through electronic patient record system [12].

In the last decade, costs of computing power hardware have come down, whereas the costs of proprietary software licenses and maintenance fees have remained almost unchanged or increased, limiting the use of such software 


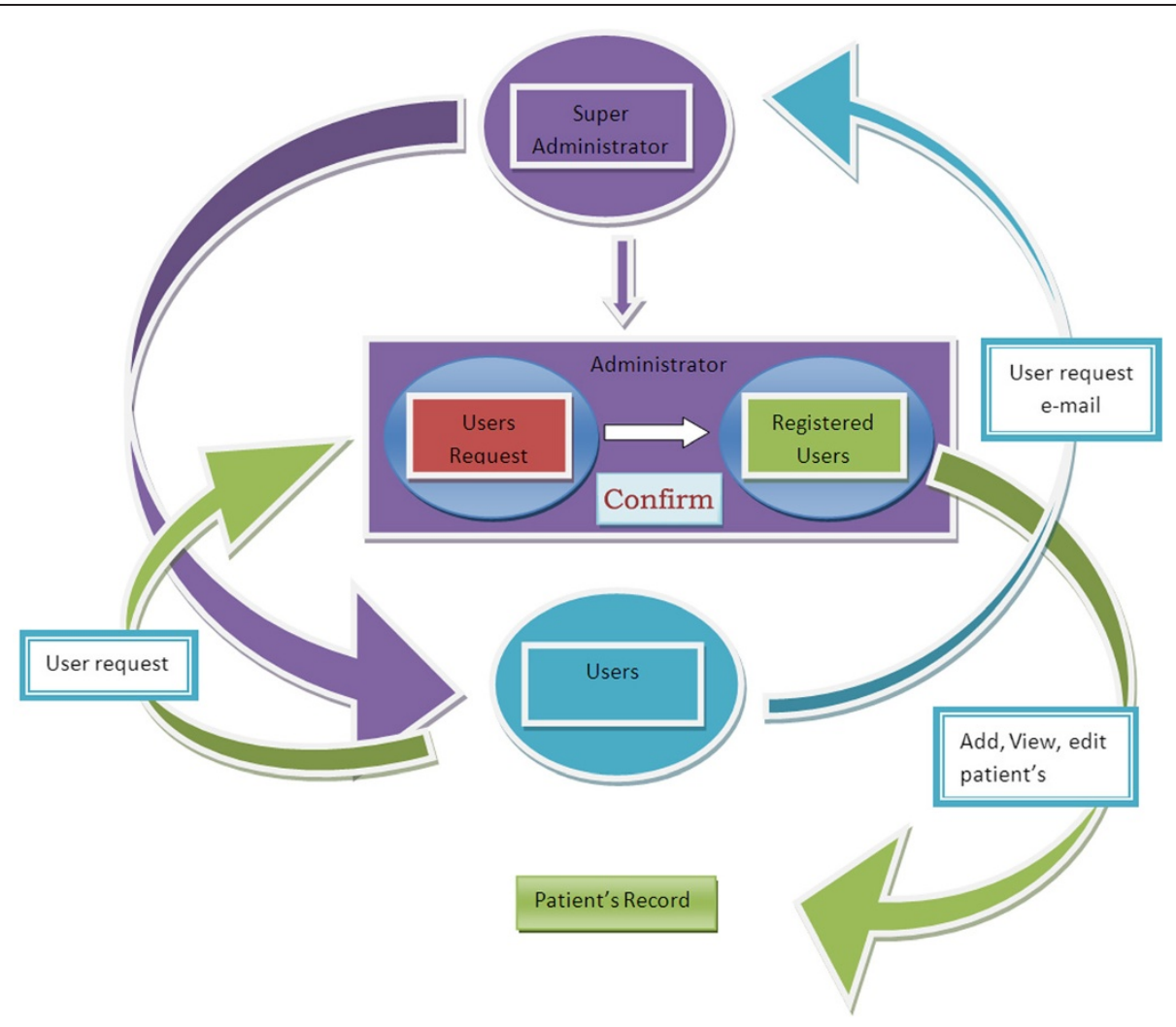

Figure 2 Showing architecture of patient's record. This figure displays patient's record management system. Patient's record is divided into three sections; personal details, case details and record history (follow-ups).

systems outside developed nations [13]. A potential solution to the barriers of standardisation, cost and business failure is free and open source software [14].

There are many barriers to the acceptance of electronic medical records by physicians. These main categories are: 1. Financial, 2. Technical, 3. Time, 4. Psychological, 5. Social, 6. Legal, 7. Organizational, and 8. Change Process [15].

Physicians who had adopted an EHR consistently reported more positive views of the potential effect of computers on health care than physicians who did not yet have an EHR [16].

\section{Construction and content \\ Database architecture}

CDKD was designed as client-server architecture with PHP5 and MySQL, running on an Apache server. PHP, MySQL and Apache technology were preferred as they are open-source components and platform independent. CDKD is hosted on both windows and Linux platform. CDKD eliminates the difficulties of maintaining a DOS based network application on computing facilities at individual hospitals. As a Web based application it is much easier to maintain and support as compared to paper based records. It can be accessible from anywhere and anytime. All graphs are dynamically generated using PHP with the GD library of image functions Figure 1.

\section{Data collection and organization}

The patient record was provided by Department of Nephrology, PGIMER, Chandigarh in excel sheets. In year 2006, the total number of patients was about 14,024. Records where information regarding any parameter (e.g. Serum creatinine) was missing were removed from the dataset.

Finally, we have excluded the data of 3,823 patients with any missing information and analyzed 10201 patient records only.

Data was grouped into six major diseases:

1. Diabetic nephropathy,

2. Chronic glomerulonephritis,

3. Congenital disease,

4. Cystic disease,

5. Obstructive uropathy and

6. Heredofamilial. 
Additionally, all records were classified into male and female groups and further subdivided with respect to their age.

Data is broadly divided into two parts i.e. personal details and lab details. A database system is designed to store the personal and laboratory investigatory details of kidney patients. Each patient's record is divided into three parts (see figure 2) i.e. personal details, case details and records history. Records history includes patient's follow-up by physician.

\section{Utility and discussion \\ Database interfaces}

The interface of CDKD is designed in a manner which helps user in easy navigation and allows use of various tools integrated in the database. The database interface includes four parts: general user, registered users, administrative users and a super user.

A. Researcher interface: The CDKD database along with its various features is described on the home page, which has links to further navigate the database. All users can access the database through researcher interface and for that there is no need of registration. User can search patient record using case id from search box available in header section. Under the advanced search option, there are four keywords, viz. basic diagnosis, gender, age group and case registration year. User can search all patient records by using any combination of these keywords or by means of at least one keyword. In basic diagnosis textbox user can use full name or part of disease name. Database statistics and tools to calculate eGFR and BMI are available in this section. User network IP address is available on this section.

Estimated glomerular filtration rate (eGFR) is measured by using the new 4-variable Modification of Diet in Renal Disease (MDRD) equation as follows [17]

$$
\begin{aligned}
\mathrm{eGFR}= & 186 \times(\text { serum } \mathrm{Cr}[\mathrm{mg} / \mathrm{dL}])^{-1.154} \\
& \times \text { age }^{-0.203} \times(0.742 \text { if female }) .
\end{aligned}
$$

Estimating GFR Using the CKD Epidemiology Collaboration (CKD-EPI) Creatinine Equation as follows [18]

$$
\begin{aligned}
\mathrm{eGFR}= & 141 \times \min (\mathrm{Scr} / \mathrm{k}, 1)^{\alpha} \times \max (\mathrm{Scr} / \mathrm{k}, 1)^{-1.209} \\
& \times 0.993^{\mathrm{age}} \times(1.018 \text { if female })
\end{aligned}
$$

Where Scr is serum creatinine $(\mathrm{mg} / \mathrm{dL}), \mathrm{k}$ is 0.7 for female and 0.9 for male, $\alpha$ is -0.329 for female and -0.411 for male.

Body mass index (BMI) is a measure of body fat based on height and weight. The formulae universally used in medicine produce a unit of measure of $\mathrm{kg} / \mathrm{m} 2$.

$$
\mathrm{BMI}=\operatorname{mass}(\mathrm{Kg}) /(\operatorname{height}(\mathrm{m})) 2
$$

B. Physician interface: Member's home page of CDKD consists of links through which physician can annotate patient's records. This section is restricted to registered users. User can add patient's personal and laboratory details in patient database and can also edit/update any patient's record through case id.

Currently, eGFR and BMI calculators are available in this section and a tool for data analysis by which a user can perform analysis of one or more parameters. There are three necessary parameters viz: gender, age group and whether to view all records or the user's own records.

User can search patient record using case id or basic diagnosis key words from search box available in header section. Physicians can search their own patient's record through this search box. Identification id provided by them, and can be used only by those who initially provide it.

Under the advanced search option, there are five keywords, viz. all record or my record, basic diagnosis, gender, age group and case registration year. User can search all

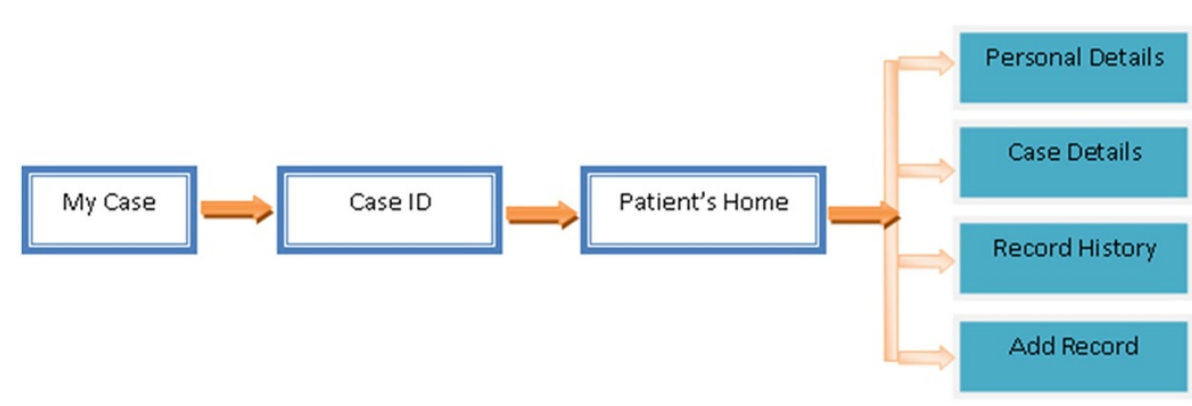

Figure 3 A flow chart explaining the registration system of CDKD. This figure explains the registration system of CDKD. This registration system is designed in such a manner so that unauthorized users cannot be registered. 


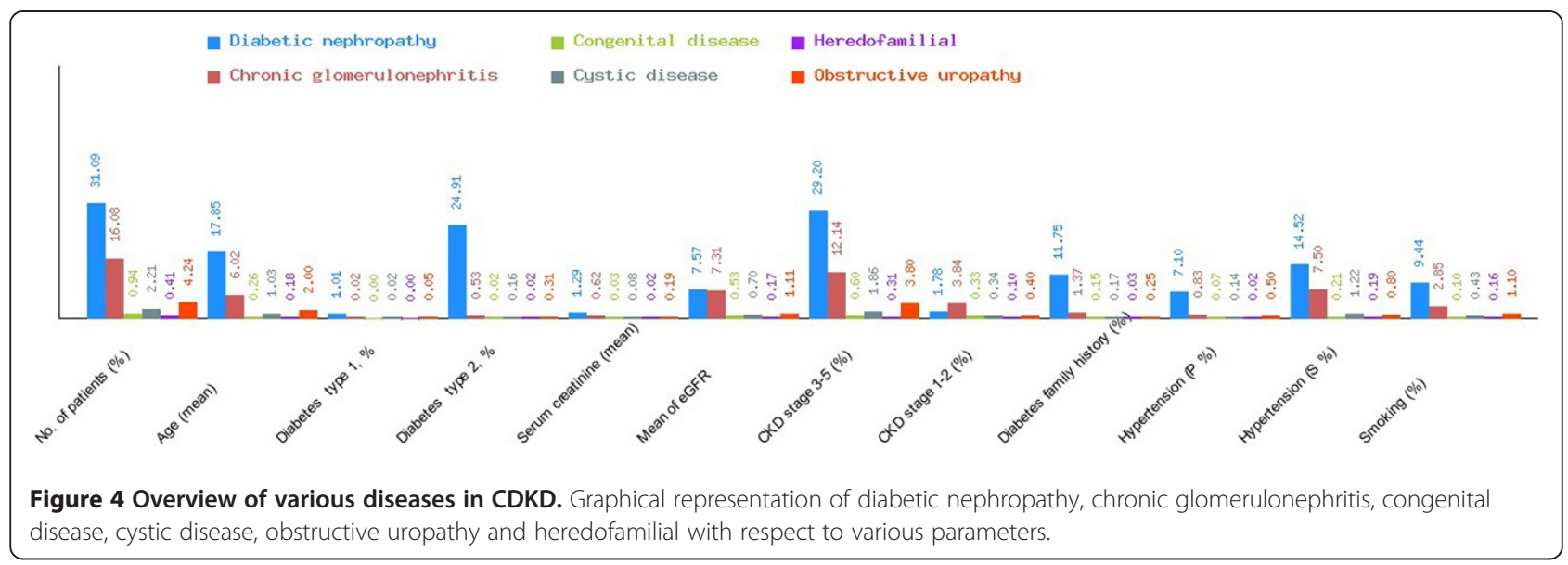

patient records by using any combination of these keywords or by means of at least one keyword. In basic diagnosis textbox user can use full name or part of disease name.

C. Administrative user interface: This area is only accessible to Administrators. From this section administrator can view all registered users. Administrator can edit/update user record. Users Request Box contains each users request for registration and when a user submits a registration form, it will appear here and later it is transferred to user request box.

D. Super user interface: This interface is accessible to super user. Super user can make administrators, and can monitor all the steps viz. registration system, which user is registered by which administrator, etc. and at the time of users request for registration an automatic system generated e-mail is sent to super user.

\section{Description}

CDKD currently contains 10,201 data entries i.e. patient records with several kidney disorders like diabetic nephropathy, chronic glomerulonephritis, etc. and is expected to grow substantially as more and more collaboration from within and outside the state are in progress.

A database system is designed to store the personal and laboratory investigatory details of Indian kidney patients. A person's medical information would be immediately available for the attending physician. Therefore if an individual needs medical care in another part of the country, the attending physicians would have the patient's entire medical history at their fingertips. Therefore, this system could provide a life saving information that would be

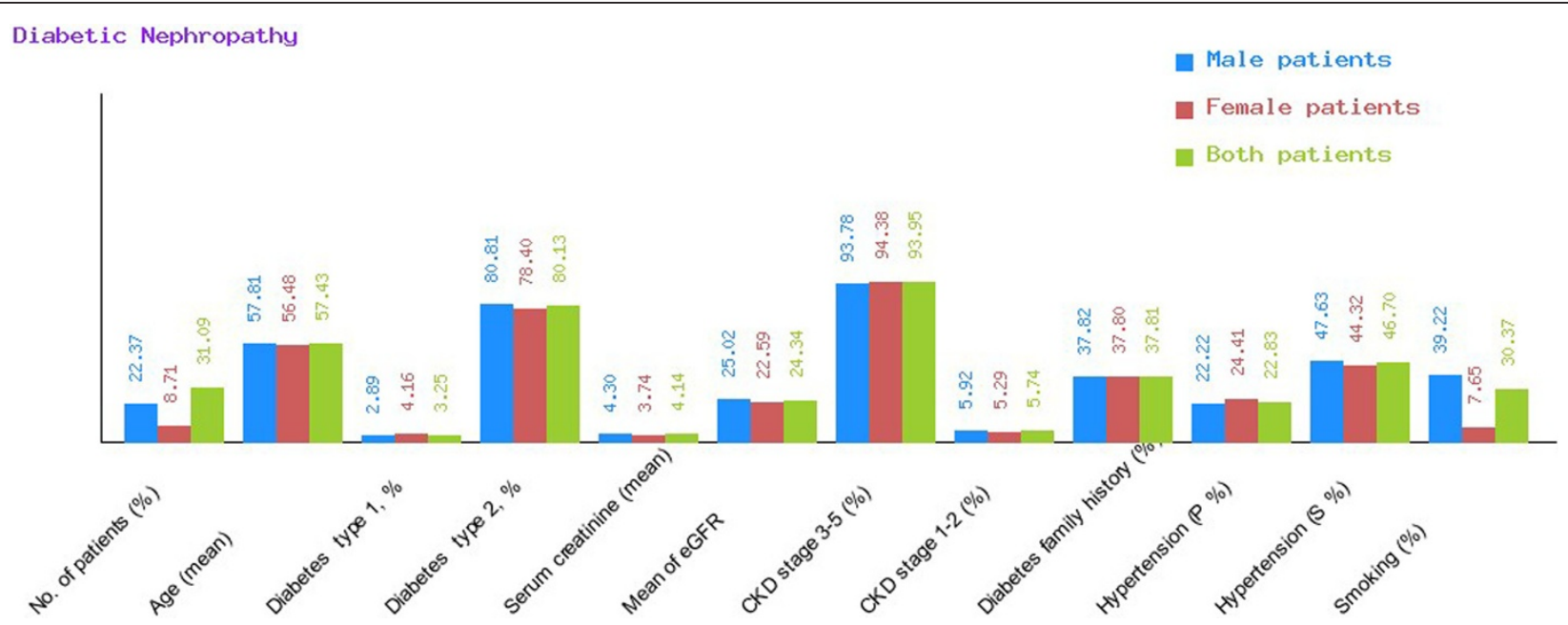

Figure 5 Graphical representation of diabetic nephropathy in CDKD. The figure shows a graphical overview of male and female patients of diabetic nephropathy present in the database. 


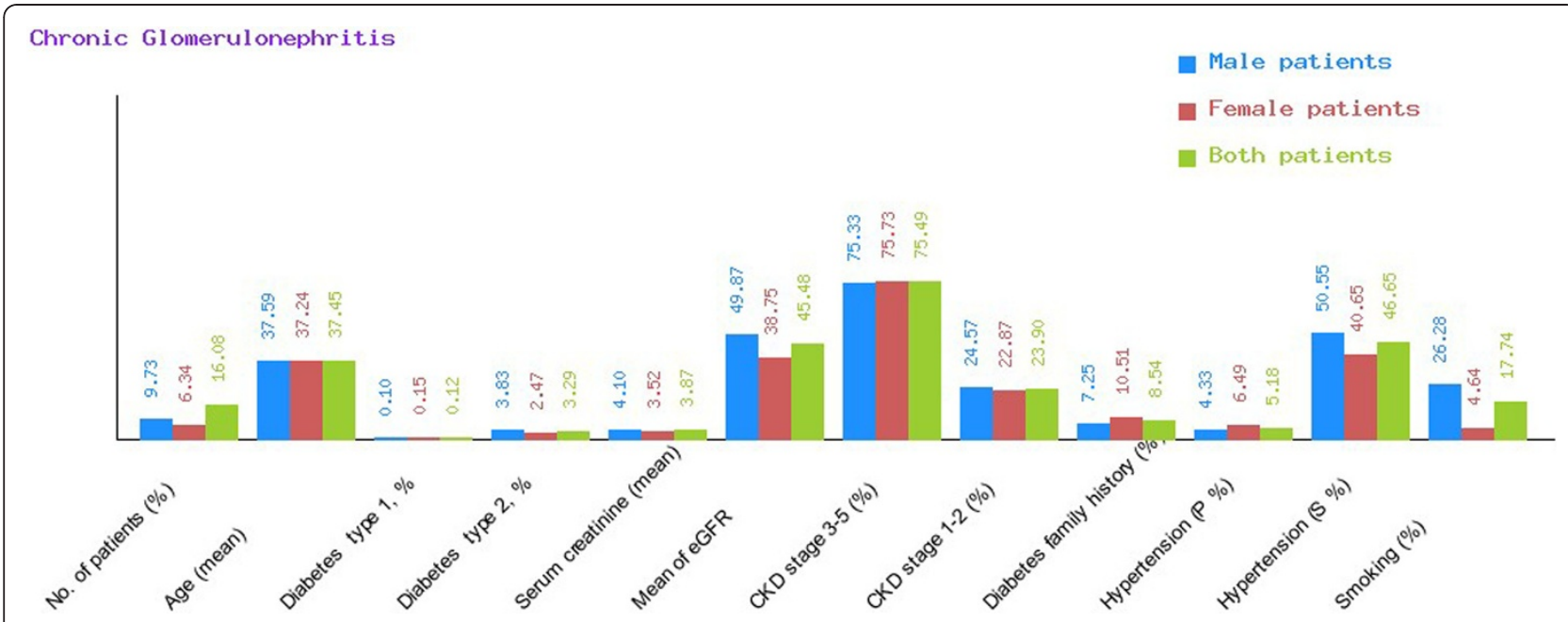

Figure 6 Graphical representations of chronic glomerulonephritis in CDKD. The figure shows a graphical overview of male and female patients of chronic glomerulonephritis present in the database.

invaluable to the attending physicians. The creation of a patient's database would also allow researchers to track certain diseases as well as to patients' responses to certain drugs. The emphasis is on experimental results relevant to quantitative renal physiology, with a particular focus on data relevant for evaluation of parameters in statistical models of renal function.

CDKD has been developed with patient confidentiality and data security as a top priority. It can make comparative analysis of one or more parameters of patient's record and includes the information of about whole range of data including demographics, medical history, laboratory test results, vital signs, personal statistics like age and weight.
This contains highly secure registration system (Figure 3). When a user registers, an e-mail is automatically sent to the super administrator. Only administrators (clinician/physicians) have rights to confirm the user request. After registration, user will receive a confirmation e-mail through administrator and only after this confirmation a user can access the database. This registration is designed in such a manner so that unauthorized users cannot be registered.

There is a security system that supports authentication and secure transmission of personal and confidential patient information. To access the patient record, the patient is identified uniquely and securely through Case ID and Identification Number; Case ID is automatically

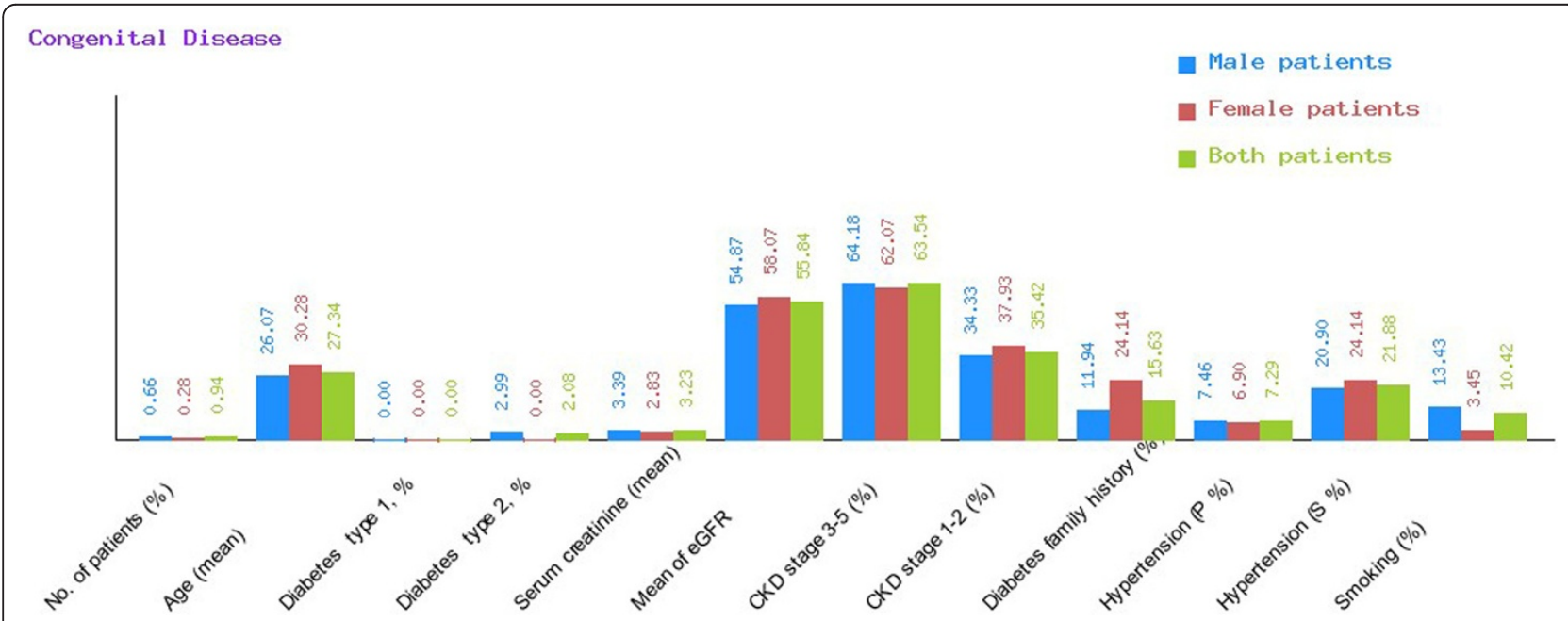

Figure 7 Graphical representation of congenital disease in CDKD. The figure shows a graphical overview of male and female patients of congenital disease present in the database. 


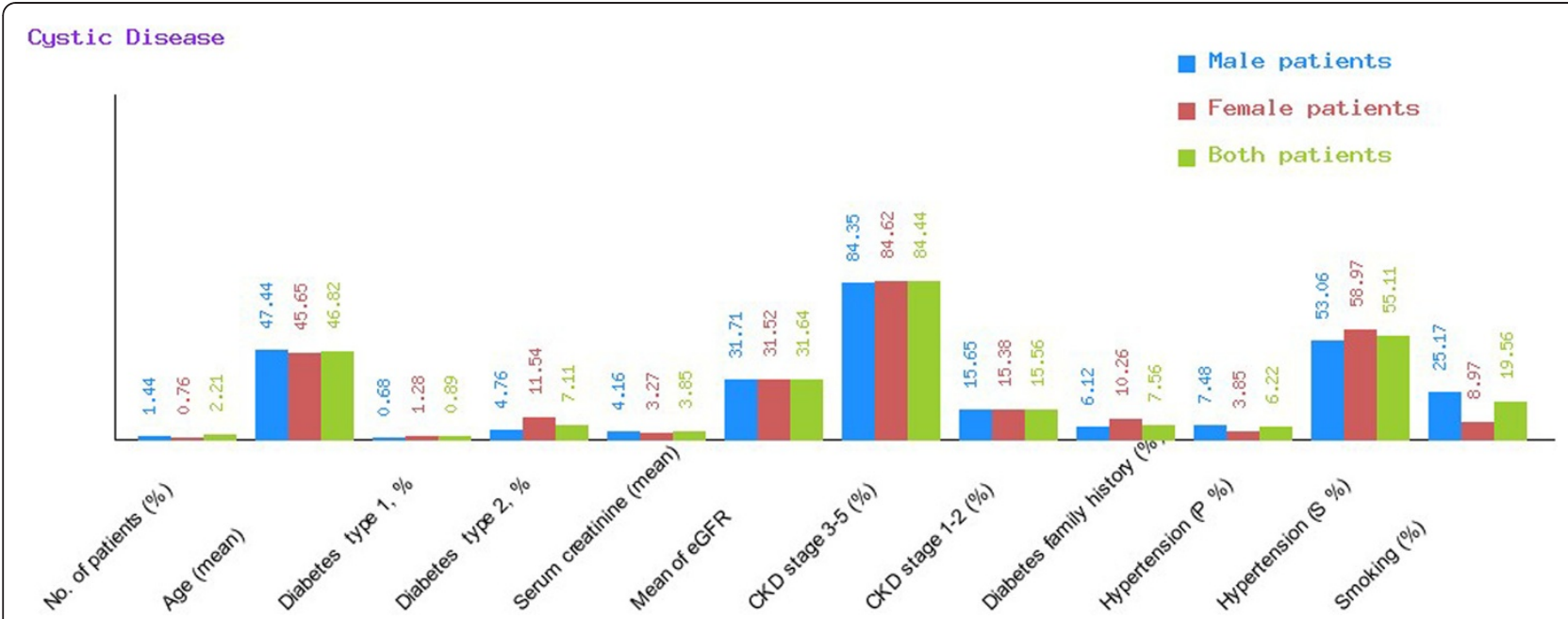

Figure 8 Graphical representation of cystic disease in CDKD. The figure shows a graphical overview of male and female patients of cystic disease present in the database.

generated at the time of case entry and Identification Number is provided by physician. As a Web based application it permits physician to see, edit and annotate a patient record from anywhere and anytime. Each physician can see the case details of all patients but not the personal data available in this database.

There is an IP address monitoring system which will track user visit and display current 10 visits on his home page so that a user can monitor his visit.

There are many barriers to the acceptance of electronic medical records by physicians. These main categories are financial, technical, time, psychological, social, legal, organizational, and change process. CDKD is designed as open-source system so there is no financial issue. It eliminates the difficulties of maintaining a DOS based network application and as a web based system all technical issues are solved quickly from our remote server. It is user friendly and only basic level of computer skill is required. The introduction of EMR doesn't affect the physician's workflow because system is designed in such a manner so that case registration will take a very short time and other details can be added at any time. EMR can successfully improve patient care or clinical outcomes.

\section{Statistical analysis}

In this work, we have analyzed the records of 10,201 patients (males $=6,776$, and females $=3,425$ ) available in CDKD. Mean age for all patients was observed to be

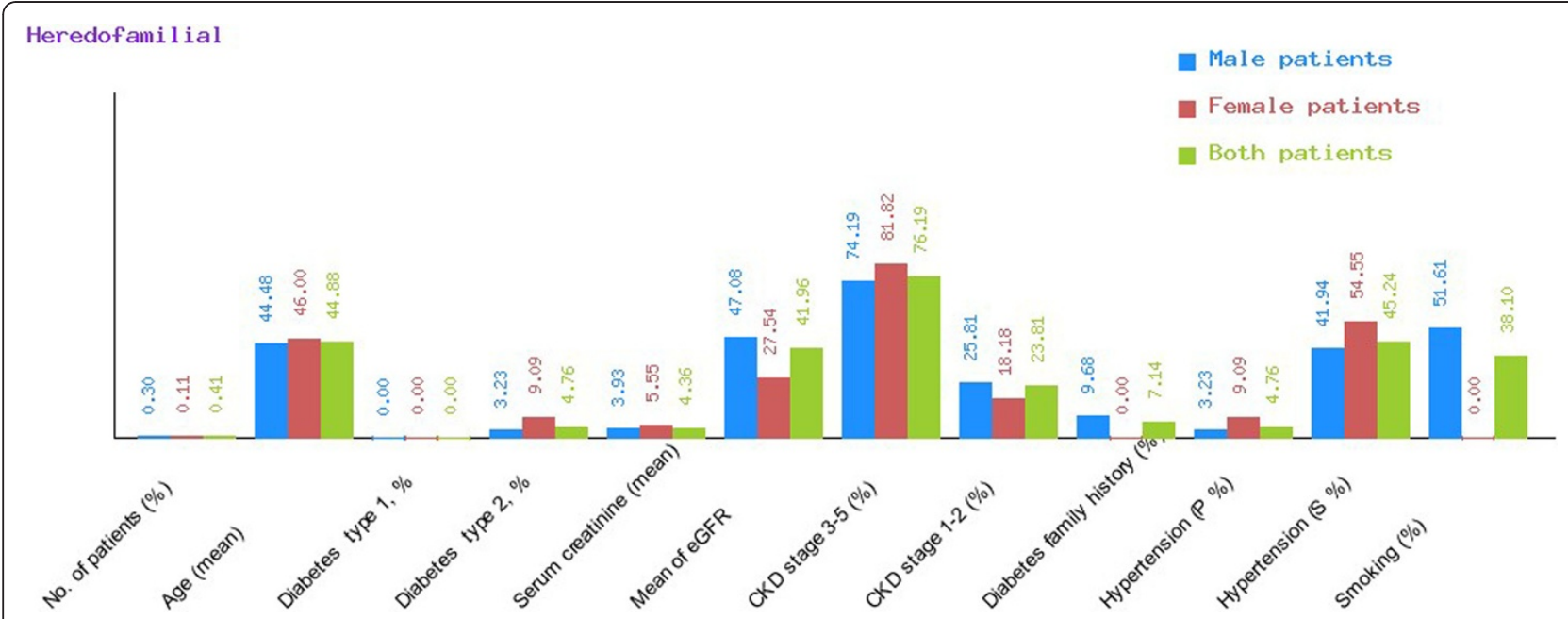

Figure 9 Graphical representation of heredofamilial in CDKD. The figure shows a graphical overview of male and female patients of heredofamilial present in the database. 


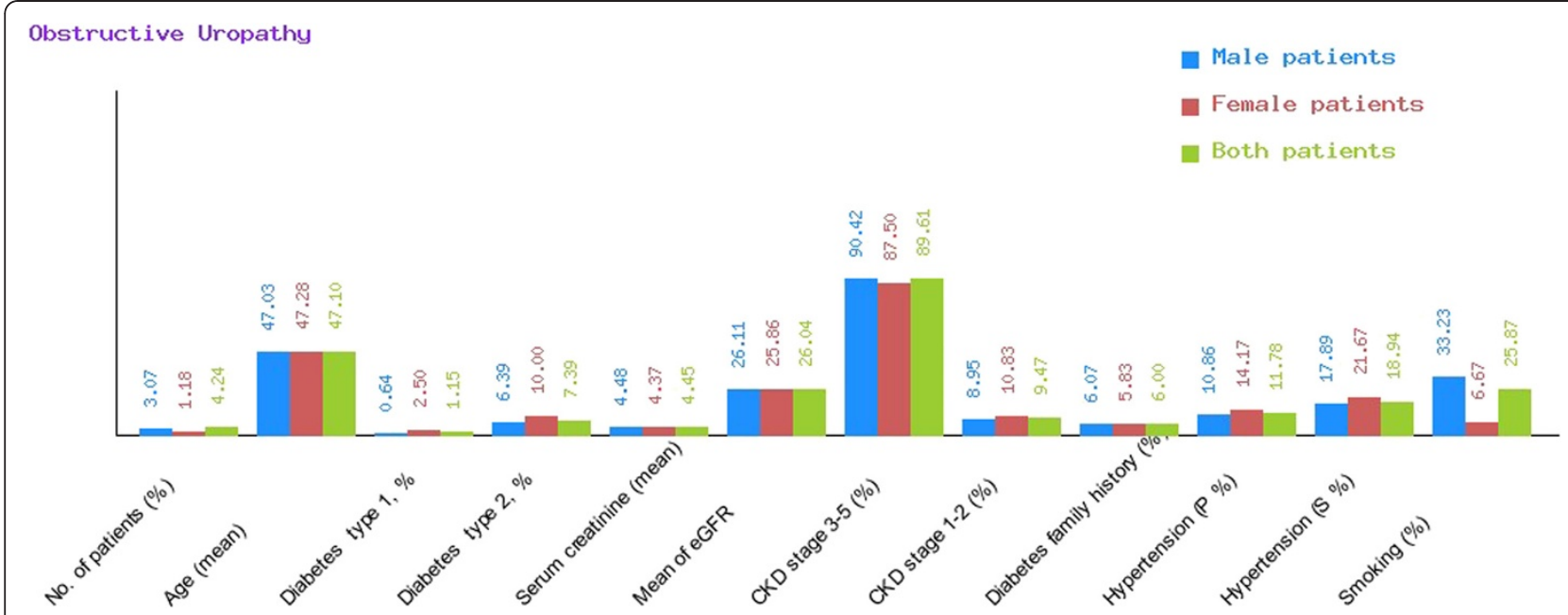

Figure10 Graphical representation of obstructive uropathy in CDKD. The figure shows a graphical overview of male and female patients of obstructive uropathy present in the database.

$48.86 \pm 16.56$ years, $49.69 \%$ were male and $47.20 \%$ female. In CDKD record, $66.42 \%$ individuals were male where as $33.58 \%$ were females. Maximum numbers of patients (35.61\%) were in age group of 45 to 59 (see Table 1).

Overall, hypertension was present in 7114 subjects (69.74\%); 4731 males (46.38\%) and 2383 females (23.36\%). In $46.38 \%$ of male patients, hypertension was primary in $22 \%$ and secondary in $39.85 \%$ whereas in $23.36 \%$ of female patients, primary and secondary hypertensions were seen in $21.63 \%$ and $36.99 \%$ respectively. Overall, the percentage of secondary hypertension $(38.89 \%)$ was more than primary hypertension (21.88\%). A total of $38.72 \%$ of the subjects had diabetes. $41.88 \%$ were male and $32.47 \%$ were female. Smoking habit was found in 2567 out of 10201 patients; 2294 were male (33.85\%) and 273 female (7.97\%) (see Table 1).

Mean eGFR was 31.90 in male and 28.08 in female. CKD status was classified into 5 stages on the basis of the eGFR values. A total of $89.03 \%$ male patients were classified in the CKD stage $3-5$ and $10.97 \%$ in the CKD stage $1-2$. Percentage of various kidney diseases in 10,102 patients within CDKD is as follows: diabetic nephropathy (30.85\%), chronic glomerulonephritis (16.08\%), congenital disease (0.94\%), cystic disease $(2.21 \%)$, obstructive uropathy $(4.24 \%)$ and heredofamilial $(0.41 \%)$ (see Table 2$)$.

Table 1 General statistics of CDKD records

\begin{tabular}{|c|c|c|c|}
\hline Factors & $\begin{array}{l}\text { Male (\%) } \\
\mathrm{n}=6776\end{array}$ & $\begin{array}{l}\text { Female (\%) } \\
\mathrm{n}=\mathbf{3 4 2 5}\end{array}$ & $\begin{array}{l}\text { Total (\%) } \\
\mathrm{n}=10201\end{array}$ \\
\hline Age (mean \pm SE) & $49.69 \pm 16.83$ & $47.20 \pm 15.88$ & $48.86 \pm 16.56$ \\
\hline Sex (population) & 66.42 & 33.58 & $100 \%$ \\
\hline \multicolumn{4}{|l|}{ Age group } \\
\hline $01-14$ & $206(3.04)$ & $83(2.42)$ & $289(2.83)$ \\
\hline $15-29$ & $722(10.66)$ & $410(11.97)$ & $1132(11.10)$ \\
\hline $30-44$ & $1296(19.13)$ & $879(25.66)$ & $2175(21.32)$ \\
\hline $45-59$ & $2428(35.83)$ & $1205(35.18)$ & $3633(35.61)$ \\
\hline$\geq 60$ & $2124(31.35)$ & $848(24.76)$ & $2972(29.13)$ \\
\hline Hypertension ( $P$ \%, S\%) & $22.00,39.85$ & $21.63,36.99$ & $21.88,38.89$ \\
\hline Diabetes (\%) & 41.88 & 32.47 & 38.72 \\
\hline BMI (mean $\pm \mathrm{SE}), \mathrm{kg} / \mathrm{m}^{2}$ & $22.47 \pm 9.24$ & $23.29 \pm 5.85$ & $22.74 \pm 8.27$ \\
\hline Smoking (\%) & 33.85 & 7.97 & 25.16 \\
\hline Creatnine (mean $\pm \mathrm{SE}$ ), $\mathrm{mg} / \mathrm{dL}$ & $4.34 \pm 2.79$ & $3.90 \pm 2.66$ & $4.19 \pm 2.76$ \\
\hline eGFR (mean $\pm \mathrm{SE}), \mathrm{mg} / \mathrm{dL}$ & $31.90 \pm 58.84$ & $28.08 \pm 51.57$ & $30.62 \pm 56.53$ \\
\hline
\end{tabular}

$n$ Number of patients, $P$ primary, $S$ secondary, SE standard deviation. 
Table 2 Comparative diseases statistics of CDKD records

\begin{tabular}{|c|c|c|c|c|c|c|}
\hline & $\begin{array}{l}\text { Diabetic } \\
\text { nephropathy }\end{array}$ & $\begin{array}{l}\text { Chronic } \\
\text { glomerulonephritis }\end{array}$ & $\begin{array}{l}\text { Congenital } \\
\text { disease }\end{array}$ & $\begin{array}{l}\text { Cystic } \\
\text { disease }\end{array}$ & Heredofamilial & $\begin{array}{l}\text { Obstructive } \\
\text { uropathy }\end{array}$ \\
\hline No. of patients $(\%)$ & $3171(31.09)$ & $1640(176.85)$ & $96(0.94)$ & $225(2.21)$ & $42(0.41)$ & $433(4.24)$ \\
\hline Age (mean $\pm S E$ ) & $57.43 \pm 10.54$ & $37.45 \pm 16.24$ & $27.34 \pm 18.81$ & $46.82 \pm 12.96$ & $44.88 \pm 14.83$ & $47.10 \pm 18.10$ \\
\hline Diabetes type 1, \% & 3.25 & 0.12 & 0.00 & 0.89 & 0.00 & 1.15 \\
\hline Diabetes type 2, \% & 80.13 & 3.29 & 2.08 & 7.11 & 4.76 & 7.39 \\
\hline $\begin{array}{l}\text { Serum creatinine } \\
(\text { mean } \pm S D)\end{array}$ & $4.14 \pm 2.54$ & $3.87 \pm 2.94$ & $3.23 \pm 2.67$ & $3.85 \pm 2.73$ & $4.36 \pm 3.16$ & $4.45 \pm 2.69$ \\
\hline Mean of eGFR & 24.34 & 45.48 & 55.83 & 31.64 & 41.96 & 26.04 \\
\hline CKD stage 3-5 (\%) & 93.95 & 75.49 & 63.54 & 84.44 & 76.19 & 89.61 \\
\hline CKD stage 1-2 (\%) & 5.74 & 23.90 & 35.42 & 15.56 & 23.81 & 9.47 \\
\hline $\begin{array}{l}\text { Diabetes family } \\
\text { history }(\%)\end{array}$ & 37.81 & 8.54 & 15.63 & 7.14 & 7.14 & 6.00 \\
\hline Hypertension (P \%, S\%) & $22.83,46.70$ & $5.18,46.65$ & $7.29,21.88$ & $6.22,55.11$ & $4.76,45.24$ & $11.78,18.94$ \\
\hline Smoking (\%) & 30.37 & 17.74 & 10.42 & 19.56 & 38.10 & 25.87 \\
\hline
\end{tabular}

We have categorized CDKD Figure 4 into diabetic nephropathy Figure 5, chronic glomerulonephritis Figure 6, congenital disease Figure 7, cystic disease Figure 8, obstructive uropathy Figure 9 and heredofamilial for Figure 10 statistical analysis relevant to number of patients (\%), age (mean $\pm \mathrm{SE}$ ), diabetes type $1, \%$, diabetes type $2, \%$, serum creatinine (mean $\pm \mathrm{SD}$ ), mean of eGFR, CKD stage 3-5 (\%), CKD stage 1-2 (\%), diabetes family history (\%), hypertension (primary \%, secondary \%) and smoking (\%) (see Table 2). All statistical tables and graphs are generated dynamically in CDKD. All diseases are further organized into age group of male and female patients.

\section{Conclusions}

The goal of this database is to make kidney-related physiological data easily available to the scientific community and to maintain \& retain patient's electronic record. The purpose of CDKD can be understood as a comprehensive documentation of patient encounters that allows the computerization and reformation of the workflow in health care settings and enhances safety through evidencebased assessment support, quality management, and outcomes treatment. Electronic records may actually be more secure than paper records. Additionally, data from such an electronic database system can be used incognito for statistical reporting in matters such as quality improvement, resource management and public health communicable disease observation.

\section{Availability of database}

The database is publicly available. Any user can access it after a free registration process. The database requires registration to check unauthorized users. CDKD is freely available at http://www.cdkd.org.

\section{Ethics}

This study was approved by the institute ethics committee of the Post Graduate Institute of Medical Education and Research (PGIMER), Chandigarh, INDIA and research was carried out in compliance with the Helsinki declaration.

\section{Consent}

Since no patient identifier appears in the database, the requirement for written consent was waived by the institute's ethics committee.

\section{Data protection}

Yes, the database adheres to all data protection requirements.

\section{Abbreviations \\ BMI: Body mass index; CDKD: A clinical database of kidney diseases; CKD: Chronic kidney disease; eGFR: Estimated glomerular filtration rate; EHR: Electronic health record; EMR: Electronic medical record.}

\section{Competing interests}

The authors declare that they have no competing interests.

\section{Authors' contributions}

SKS developed the database architecture and carried out statistical analysis. AF \& SKS created the web interface and performed the validations. The patient records were provided by VJ AM \& VJ conceived the original idea and supervised the work. SKS and AM drafted the manuscript, with SKS in the lead and each author advised on it. All authors read and approved the final manuscript.

\section{Acknowledgements}

The financial support from the Indian Council of Medical Research (ICMR) is gratefully acknowledged.

\section{Author details}

${ }^{1}$ Biomedical Informatics Centre, Post Graduate Institute of Medical Education and Research (PGIMER), Chandigarh 160012, India. ${ }^{2}$ Department of Nephrology, Post Graduate Institute of Medical Education and Research (PGIMER), Chandigarh 160012, India. ${ }^{3}$ School of Computational Sciences, 
Received: 21 November 2011 Accepted: 17 April 2012

Published: 27 April 2012

\section{References}

1. Agarwal SK: Chronic kidney disease and its prevention in India. Kidney Int 2005, 68(Supplement 98):S41-S45.

2. United States Renal Data System: USRDS 2007 Annual Data Report. Bethesda: National Institute of Diabetes and Digestive and Kidney Diseases, National Institutes of Health, U.S. Department of Health and Human Services; 2007.

3. Sakhuja V, Kohli HS: End-stage renal disease in india and pakistan: Incidence, causes, and management. Ethn Dis. 2006, Spring; 16(2 Suppl 2):S2-20-3.

4. Unnikrishnan RI, Rema M, Pradeepa R, Deepa M, Shanthirani CS, Deepa R, Mohan V: Prevalence and risk factors of diabetic nephropathy in an urban South Indian population: the Chennai Urban Rural Epidemiology Study (CURES 45). Diabetes Care 2007, 30(8):2019-2024.

5. Viswanathan V: Prevention of diabetic nephropathy: a diabetologist's perspective. Indian J Nephrol 2004, 14:157-162.

6. Levey AS, Eckardt KU, Tsukamoto Y, Levin A, Coresh J, Rossert J, De Zeeuw D, Hostetter TH, Lameire N, Eknoyan G: Definition and classification of chronic kidney disease: a position statement from Kidney Disease: Improving Global Outcomes (KDIGO). Kidney Int 2005, 67:2089-2100.

7. Tsukamoto Y, Jha V, Becker G, Chen HC, Perkovic V, Prodjosudjadi W, Tungsanga $\mathrm{K}$, Wang $\mathrm{H}$, Morad Z: A challenge to chronic kidney disease in Asia: the report of the second Asian forum of chronic kidney disease initiative. Nephrology 2010, 15:248-252.

8. Chugh KS, Jha V, Chugh S: Economics of dialysis and renal transplantation in the developing world. Transplant Proc 1999, 31:3275-3277.

9. Meinert DB: Resistance to Electronic Medical Records (EMRs): a barrier to improved quality of care. Issues in Informing Sci \& Inf Technol 2005, 2:493-504.

10. Jones BE, Ould MA: The patient medical record as a database. Comput J 1974, 17:4.

11. Bhuvaneswari T, Dutta N, Srivasta SK: Distributed virtual patient record system. Inf Technol J 2007, 6(5):766-770.

12. Valdes I, Kibbe DC, Tolleson G, Kunik ME, Petersen LA: Barriers to proliferation of electronic medical records. Inform Prim Care 2004, 12(1):3-9.

13. Marques ET Jr, Maciel Filho R, August PN: Overcoming health inequity: potential benefits of a patient-centered open-source public health infostructure. Cad Saude Publica 2008, 24(3):547-557.

14. Carnall D: Medical software's free future. BMJ 2001 Oct 21; 321(7267):976.

15. Boonstra, Broekhuis: Barriers to the acceptance of electronic medical records by physicians from systematic review to taxonomy and interventions. BMC Health Serv Res 2010, 10:231.

16. Simon SR, Kaushal R, Cleary PD, Jenter CA, Volk LA, Orav EJ, Burdick E, Poon EG, Bates DW: Physicians and electronic health records: a statewide survey. Arch Intern Med. 2007 Mar 12; 167(5):507-12.

17. Levey AS, Coresh J, Greene T, Stevens LA, Zhang YL, Hendriksen S, Kusek JW, Van Lente F: Using standardized serum creatinine values in the modification of diet in renal disease study equation for estimating glomerular filtration rate. Ann Intern Med 2006, 145:247-254.

18. Levey AS, Stevens LA, Schmid CH, et al: A new equation to estimate glomerular filtration rate. Ann Intern Med 2009, 150:604-612.

doi:10.1186/1471-2369-13-23

Cite this article as: Singh et al.: CDKD: a clinical database of kidney diseases. BMC Nephrology 2012 13:23.

\section{Submit your next manuscript to BioMed Central and take full advantage of:}

- Convenient online submission

- Thorough peer review

- No space constraints or color figure charges

- Immediate publication on acceptance

- Inclusion in PubMed, CAS, Scopus and Google Scholar

- Research which is freely available for redistribution

Submit your manuscript at www.biomedcentral.com/submit 